\title{
Special issue: select papers from the 29th Northern Ireland Biomedical Engineering Conference, Belfast, UK, April 2009
}

\author{
Nicholas J. Dunne · Fraser J. Buchanan • \\ Adrian R. Boyd · George A. Burke
}

Published online: 18 June 2010

(C) Springer Science+Business Media, LLC 2010

\begin{abstract}
Each year, NIBES hosts a spring conference that is jointly organised by Queen's University of Belfast and University of Ulster. The 29th NIBES Spring meeting took place on 8th April 2009 at Queen's University of Belfast. NIBES 2009 had an impressive scientific program with two international leading plenary speakers and 28 oral presentations.
\end{abstract}

Keywords Biomedical engineering $\cdot$ Biomaterials

The Northern Ireland Biomedical Engineering Society (NIBES), which was constituted in 1979, was founded in order to provide a forum for communication between all those interested in biomedical engineering. Since its establishment the society has been involved in building up a strong biomedical engineering community within Northern Ireland.

The key aims of NIBES are:

(1) To promote biomedical engineering,

(2) To provide a forum for communication between all those interested in biomedical engineering,

(3) To encourage collaborations within the biomedical engineering community (locally, nationally and internationally),

N. J. Dunne ( $\square)$. F. J. Buchanan

School of Mechanical \& Aerospace Engineering,

Queen's University of Belfast, Ashby Building,

Stranmillis Road, Belfast BT9 5AH, Northern Ireland, UK

e-mail: n.dunne@qub.ac.uk

A. R. Boyd · G. A. Burke

School of Engineering, University of Ulster, Jordanstown campus, Shore Road, Newtownabbey BT37 0QB, Northern Ireland, UK
(4) To promote the teaching of biomedical engineering to undergraduate and postgraduate students,

(5) To provide meetings to encourage the dissemination of information and education in matters related to biomedical engineering.

Currently NIBES has an active membership of more than 70 members from a variety of backgrounds including, academia, industry, government and clinically related professions and currently promotes diverse interests in a range of areas, including;

Each year, NIBES hosts a spring conference that is jointly organised by Queen's University of Belfast and University of Ulster. The 29th NIBES Spring meeting took place on 8th April 2009 at Queen's University of Belfast. NIBES 2009 had an impressive scientific program with two international leading plenary speakers and 28 oral presentations. The plenary lectures were given by Dr. Michael Tunney (School of Pharmacy, Queen's University of Belfast) and Associate Professor Fergal O'Brien (Department of Anatomy, Royal College of Surgeons Ireland), respectively. Dr. Tunney's paper focussed on improving detection and treatment of prosthetic joint infection and Professor O'Brien gave an insight into the potential application of collagen based scaffolds for orthopaedic regenerative medicine. The high quality oral papers presented at NIBES 2009 crossed a number of different thematic areas, including biomaterials, medical devices, biological response, modelling and bioinformatics. Miss Rochelle O'Hara (Queen's University of Belfast) and Miss Eilish McGrath (University College Dublin) were recipients of the awards for best student papers and Dr. Rachelle D'Sa (University of Ulster) and Dr. Nicholas Dunne (Queen's University of Belfast) for best oral papers.

NIBES 2009 successfully bridged the gap between fundamental biomaterial/biomedical research and current 
clinical problems promoting translational research and was the forum to disseminate basic, applied and clinical research in a multi-disciplinary environment. This special issue of JMSMM is a compilation of invited papers proposed by the reviewers during the reviewing and selection process. We hope that this special issue will be of interest to the entire readership and that it may stimulate further interest in biomaterials and biomedical engineering.

Finally, the conference organisers would like to thank all academic institutions, societies and companies that have supported NIBES 2009 and also recognise the considerable efforts of the council members and reviewers that have assisted to organise the scientific program and industrial exhibition. 